\title{
Jurnal
}

Manajemen Kesehatan Indonesia

Volume 7

Nomor 3

Desember 2019

\section{Gambaran Kepesertaan JKN Tahun 2019}

\author{
Nurvita, Silvia \\ Mahasiswa Sekolah Pasca Sarjana Universitas Diponegoro \\ Pasca Sarjana Kesehatan Masyarakat Universitas Diponegoro \\ Email:nurvitasilvia@gmail.com
}

\section{ABSTRACT}

National Health Insurance (JKN) is a program of the National Social Security System with the principle of social health insurance that is mandatory for the Indonesian population under Law No. 40 of 2004. The National Health Insurance has been implemented by the BPJS since January 1, 2014. BPJS of Health is a public legal entity that coordinates directly under the President and in 2019 all Indonesian people have to become JKN participants to make Universal Health Coverage (UHC). The purpose of this study was to study the JKN participant in 2019. This study used a descriptive type of research. The subject of this study is the all population of Indonesia. This study will discuss the number of JKN participants, types of JKN participation, rights and obligations, procedures for registration, cost, and how to use a National Health Insurance card. The results of this study show data from BPJS of Health on August 8, 2014 that National Health Insurance participants $126,487,166$ people from total population 257,5 million. JKN participation continues to increase every year until 2019. Data from BPJS Health of JKN participants as of April 1, 2019 amounted to 219,669,453 people with a total PBI-APBN 96,517,386 people, PBI-APBD 35,925,726 people, PPU $P N$ 17,279,621 people, PPU-BU 33,187,465 people, PBPU 31,600,985 people, and Not
Workers 5,158,270 people. In 2019 all Indonesia people became JKN participants. The conclusion that the number of JKN participants continued to increase, April 1, 2019 JKN participants 219.669 .453 people from total population 257,5 million and in 2019 Indonesia be expected UHC. Suggestions this research, companies that have not yet register their employees in JKN and people have not yet become JKN participants are immediately register through the office / website BPJS of Health or care center 1500400, Mobile JKN, e-DABU.

Keywords: Participation, JKN, BPJS of Health, $U H C$

\section{PENDAHULUAN}

Setiap orang berhak atas jaminan sosial sesuai UUD 1945 pasal $28 \mathrm{H}$. Berdasarkan pasal tersebut pemerintah mengembangkan dan membentuk Undang Undang Sistem Jaminan Sosial Nasional (SJSN) bagi seluruh rakyat Indonesia. ${ }^{1}$ SJSN adalah sistem pemberian jaminan kesejahteraan yang berlaku kepada semua warga negara dan sifatnya adalah dasar. ${ }^{2}$ Undang - Undang Nomor 40 Tahun 2004 tentang Sistem Jaminan Sosial Nasional (SJSN) bertujuan untuk memberikan jaminan sosial yang menyeluruh bagi penduduk Indonesia. Jenis program jaminan sosial menurut 
Undang - Undang Nomor 40 Tahun 2004 salah satunya yaitu Jaminan Kesehatan Nasional $(\mathrm{JKN})$. Jaminan Kesehatan Nasional (JKN) merupakan asuransi sosial dengan prinsip utama gotong - royong dan kepesertaannya bersifat wajib bagi seluruh penduduk Indonesia berdasarkan UU No. 40 Tahun 2004. ${ }^{3}$ Rys mengatakan asuransi sosial sebagai dasar jaminan sosial dimana jaminan sosial adalah seluruh rangkaian langkah wajib yang dilakukan oleh masyarakat untuk melindungi mereka dan keluarga mereka dari segala akibat yang muncul karena gangguan yang tidak terhindarkan, atau karena berkurangnya penghasilan yang mereka butuhkan untuk mempertahankan taraf hidup yang layak. ${ }^{4}$ Program Jaminan Kesehatan Nasional sudah mulai dilaksanakan oleh Badan Penyelenggara Jaminan Sosial (BPJS) Kesehatan sejak 1 Januari 2014. BPJS Kesehatan merupakan badan hukum publik yang koordinasi langsung dibawah Presiden yang dibentuk untuk mensukseskan program Jaminan Kesehatan Nasional (JKN) BPJS Kesehatan dibentuk atas dasar Undang - Undang Nomor 24 Tahun 2011 tentang BPJS Pasal 14 yang tertulis bahwa setiap orang, termasuk orang asing yang bekerja dan tinggal paling singkat 6 bulan di Indonesia wajib menjadi peserta $\mathrm{JKN}^{5}$ Kepesertaan yang bersifat wajib bagi rakyat Indonesia itulah yang membuat BPJS menargetkan pada 1 Januari 2019 seluruh penduduk Indonesia yang berjumlah 257,5 juta jiwa menjadi peserta Jaminan Kesehatan Nasional (JKN) untuk mewujudkan Universal Health Coverage (UHC). Universal Health Coverage (UHC) adalah cakupan kesehatan yang menyeluruh bagi seluruh penduduk Indonesia. ${ }^{6}$ Berdasarkan data yang diterbitkan BPJS Kesehatan 8 Agustus 2014 peserta jaminan kesehatan nasional sebesar 126.487.166 jiwa $^{7}$ terus bertambah sebesar 156,7 juta jiwa tahun 2015 dan tahun 2018 kepesertaan jaminan kesehatan nasional menjadi 235,1 juta jiwa 2018 dan ditahun 2019 diperkirakan BPJS Kesehatan dapat mencapai target kepesertaan JKN. $^{6}$ Berdasarkan hal tersebut peneliti tertarik meneliti tentang kepesertaan JKN. Penelitian ini bertujuan untuk mengetahui gambaran kepesertaan JKN di Tahun 2019. Penelitian ini juga akan menggambarkan jenis-jenis kepesertaan JKN, hak dan kewajiban peserta, tata cara pendaftaran, iuran dan cara penggunaan kartu jaminan kesehatan nasional.

\section{METODE PENELITIAN}

Penelitian ini menggunakan jenis penelitian deskriptif. Metode pengumpulan data dilakukan dengan studi literatur melalui jurnal, buku, peraturan presiden, undang undang. Subjek penelitian ini seluruh penduduk Indonesia.

\section{HASIL DAN PEMBAHASAN \\ Gambaran Jenis Kepesertaan JKN}

Kepesertaan BPJS Kesehatan dibagi menjadi dua kelompok sesuai Peraturan Presiden No. 82 Tahun 2018, yaitu Peserta Penerima Bantuan Iuran (PBI) Jaminan Kesehatan Nasional dan Peserta Bukan Penerima Bantuan Iuran (Non-PBI) Jaminan Kesehatan Nasional. Penerima Bantuan Iuran (PBI) Jaminan Kesehatan Nasional yang ditetapkan oleh menteri yang menyelenggarakan urusan pemerintahan di bidang sosial dan didaftarkan oleh menteri sebagai peserta ke BPJS Kesehatan. Bayi yang dilahirkan oleh ibu kandung yang terdaftar sebagai peserta PBI JKN secara otomatis ditetapkan sebagai peserta PBI JKN sesuai peraturan perundang-undangan. Pekerja Bukan PBI JKN terdiri dari Penerima Upah (PBPU) dan anggota keluarganya, Bukan Pekerja (BP) dan anggota keluarganya. Pekerja Penerima Upah (PPU) dan anggota keluarganya (suami/ istri dan 3 orang anak) terdiri atas Pegawai Negeri Sipil, Anggota TNI, Polri, Pejabat Negara, Pegawai Pemerintah Non Pegawai Negeri, Pegawai swasta, Pekerja lainnya yang menerima Upah. Pekerja Bukan Penerima Upah yaitu pekerja mandiri. Kepesertaan Jaminan Kesehatan Nasional jenis Bukan Pekerja (BP) meliputi Investor, Pemberi Kerja, Penerima pensiun, Veteran, Perintis Kemerdekaan. ${ }^{8}$ 


\section{Gambaran Hak dan Kewajiban Peserta JKN}

Peserta Jaminan Kesehatan Nasional (JKN) memiliki hak dan kewajiban saat terdaftar sebagai peserta. Hak peserta Jaminan Kesehatan Nasional (JKN) sebagai berikut: ${ }^{9}$

1. Peserta mendapatkan kartu JKN sebagai bukti sah untuk mendapatkan pelayanan kesehatan

2. Memperoleh manfaat dan informasi tentang hak dan kewajiban serta prosedur pelayanan kesehatan sesuai dengan ketentuan yang berlaku

3. Mendapatkan pelayanan kesehatan di fasilitas kesehatan yang bekerjasama dengan BPJS Kesehatan

4. Menyampaikan keluhan, kritik dan saran secara lisan atau tertulis

Kewajiban peserta Jaminan Kesehatan Nasional (JKN) yakni:

1. Mendaftarkan dirinya sebagai peserta JKN dan membayar iuran setiap bulan

2. Melaporkan perubahan data peserta, baik karena pernikahan, perceraian, kematian, kelahiran, pindah alamat, atau pindah fasilitas kesehatan tingkat pertama

3. Menjaga kartu JKN peserta agar tidak rusak, hilang atau dimanfaatkan oleh orang yang tidak bertanggung jawab

4. Mentaati semua ketentuan dan tata cara pelayanan kesehatan

Gambaran Tata Cara Pendaftaran, Iuran, dan Cara Penggunaan Kartu JKN

Proses pendaftaran menjadi peserta

BPJS Kesehatan sesuai Peraturan BPJS Kesehatan No. 1 Tahun 2014 dapat dilakukan secara kolektif maupun perorangan. ${ }^{9,10}$

a. Persyaratan pendaftaran perorangan bagi Pekerja Penerima Upah contohnya untuk pegawai negeri sipil mengisi Formulir Daftar Isian Peserta (FDIP) yang di tanda tangani oleh pimpinan unit kerja dan stempel unit kerja, serta menunjukkan dokumen sebagai berikut :
- $\quad$ Asli/foto copy SK PNS terakhir;

- Asli/foto copy Daftar Gaji yang dilegalisasi oleh pimpinan unit kerja;

- $\quad$ Asli/foto copy KP4 yang dilegalisasi

- Asli/foto copy Kartu Keluarga dan KTP (diutamakan KTP elektronik);

- $\quad$ Foto copy surat nikah;

- Foto copy akte kelahiran anak/surat keterangan lahir/SK Pengadilan Negeri untuk satu anak angkat yang ditanggung;

- Surat Keterangan dari sekolah/ perguruan tinggi (bagi anak berusia lebih dari 21 tahun sampai dengan usia ke 25 tahun)

b. Persyaratan pendaftaran perorangan untuk pegawai swasta yakni Pegawai Swasta / Badan Usaha mengisi Formulir Daftar Isian Peserta (FDIP) yang di tanda tangani oleh pimpinan unit kerja dan stempel unit kerja serta menunjukkan dokumen sebagai berikut :

- Bukti diri sebagai Tenaga Kerja / karyawan aktif pada perusahaan;

- Perjanjian Kerja/SK pengangkatan sebagai pegawai

- Asli/foto copy Kartu Keluarga dan KTP (diutamakan KTP elektronik);

- Fotocopy daftar gaji yg telah dilegalisasi pimpinan unit kerja

- Foto copy surat nikah;

- Foto copy akte kelahiran anak/surat keterangan lahir

- Foto copy Pengadilan Negeri untuk anak angkat

- Bagi WNA menunjukkan Kartu Ijin Tinggal Sementara/Tetap (KITAS/KITAP)

Pendaftaran, perubahan data pegawai swasta/badan usaha dapat didaftarkan pemberi kerja (badan usaha) secara online melalui e-DABU dan pada e-DABU badan usaha dapat mengetahui rincian tagihan iuran yang harus dibayarkan setiap bulan.

C. Pendaftaran secara perorangan untuk Pekerja Bukan Penerima Upah (PBPU) 
meliputi mengisi Formulir Daftar Isian Peserta (FDIP), serta memperlihatkan dokumen sebagai berikut:

- Asli/foto copy Kartu Keluarga dan KTP (diutamakan KTP elektronik);

- Foto copy surat nikah

- Foto copy akte kelahiran anak/surat keterangan lahir yang menjadi tanggungan.

- Bagi WNA menunjukan Kartu Ijin Tinggal Sementara/Tetap (KITAS/KITAP)

Peraturan Presiden No. 82 Tahun 2018 mengamanatkan setiap orang bukan Pekerja wajib mendaftarkan dirinya dan anggota keluarganya sebagai peserta Jaminan Kesehatan Naional ke BPJS Kesehatan dan membayar iuran. ${ }^{8}$

d. Pendaftaran secara perorangan untuk salah satunya Bukan Pekerja yakni Pemberi Kerja meliputi mengisi Formulir Daftar Isian Peserta (FDIP), dengan memperlihatkan dokumen yaitu:

- Asli/foto copy Kartu Keluarga/KTP

- Bagi WNA menunjukkan Kartu Ijin Tinggal Sementara/Tetap (KITAS/KITAP).

Setiap Pemberi Kerja wajib mendaftarkan dirinya dan Pekerjanya sebagai Peserta Jaminan Kesehatan kepada BPJS Kesehatan dengan membayar iuran sesuai peraturan Peraturan Presiden No. 82 Tahun $2018 .^{8}$

Iuran peserta Jaminan Kesehatan Nasional diatur dalam Peraturan Presiden No. 82 Tahun 2018. Iuran peserta Jaminan Kesehatan Nasional dibagi menjadi iuran PBI dan iuran bukan PBI. Peserta yang terdaftar sebagai penerima bantuan iuran (PBI) tidak mengeluarkan biaya untuk pembayaran iuran Jaminan Kesehatan Nasional (JKN) secara pribadi melainkan pembayaran iuran tersebut sudah ditanggung pemerintah menggunakan anggaran APBN atau APBD.

Iuran peserta bukan PBI untuk peserta Pekerja Penerima Upah (PPU) yang terdiri atas Pegawai Negeri Sipil, Anggota TNI, Anggota
Polri, Pejabat Negara, dan Pegawai Pemerintah Non Pegawai Negeri sebesar 5\% (lima persen) dari gaji atau upah per bulan. Iuran sebagaimana dimaksud dibayar dengan ketentuan sebagai berikut:

a. 3\% (tiga persen) dibayar oleh Pemberi Kerja

b. $2 \%$ (dua persen) dibayar oleh Peserta, jika peserta menambahkan keluarga tambahan (orang tua, mertua anak ke 4 dan seterusnya maka iuran peserta ditambah $1 \%$ setiap anggota yang ditambahkan

Peserta Pekerja Penerima Upah (Pegawai Swasta) Iuran Jaminan Kesehatan Nasional (JKN) bagi peserta penerima upah pegawai swasta atau badan usaha (PPU - BU) sebesar 5\% (lima persen) dari gaji atau upah per bulan dengan ketentuan yaitu:

a. 4\% (empat persen) dibayar oleh Pemberi Kerja

b. $1 \%$ (satu persen) dibayar oleh Peserta, jika peserta menambahkan keluarga tambahan (orang tua, mertua anak ke 4 dan seterusnya maka iuran peserta ditambah $1 \%$ setiap anggota yang ditambahkan

Kategori hak kelas perawatan dalam pelayanan kesehatan untuk pegawai penerima upah hanya terdapat Kelas I dan Kelas II. Kelas I untuk gaji karyawan lebih dari 4 juta rupiah dan untuk gaji karyawan kurang dari sama dengan 4 juta rupiah tergolong mendapatkan hak perawatan Kelas II. Iuran Jaminan Kesehatan untuk setiap Peserta Bukan Penerima Upah / Pekerja Mandiri (PBPU) dan bukan pekerja meliputi:

Kelas I iuran sebesar : Rp. 80.000,00

Kelas II iuran sebesar : Rp. 51.000,00

Kelas III iuran sebesar : Rp. 25.500,00

Pembayaran iuran bagi peserta yang kategori bukan penerima bantuan iuran dilakukan tanggal $1-10$ setiap bulan dengan menggunakan nomor virtual account/nomor peserta yang terdapat di kartu JKN. Pembayaran iuran JKN karyawan badan usaha/perusahaan dilakukan oleh badan usaha/perusahaan setiap tanggal $1-10$ setiap bulan sesuai tagihan iuran badan 
usaha/perusahaan yang ditetapkan BPJS Kesehatan. Pembayaran iuran untuk badan usaha/perusahaan menggunakan virtual account badan usaha masing - masing. Peserta JKN dapat mengetahui semua informasi tentang JKN seperti iuran, tata cara pendaftaran, perubahan data kepesertaan dan fasilitas kesehatan, keluhan, dan lainnya pada aplikasi Mobile JKN yang dapat diunduh di smart phone peserta atau website BPJS Kesehatan atau care center 1500400.

Peserta yang sudah memiliki kartu peserta JKN dan terdaftar peserta aktif (tidak memiliki tunggakan iuran) dapat memanfaatkan pelayanan kesehatan di fasilitas kesehatan tingkat pertama (FKTP) yang sudah peserta pilih dan tercetak di kartu JKN masing - masing peserta. Jika peserta dalam kondisi gawat darurat/emergency dapat langsung ke IGD rumah sakit yang bekerjasama dengan BPJS Kesehatan.

\section{Gambaran Kepesertaan JKN di Tahun 2019}

BPJS Kesehatan pada 8 Agustus 2014 mempublikasikan pencapaian peserta jaminan kesehatan nasional sebesar 126.487.166 jiwa sejak BPJS Kesehatan dibentuk pada 1 April 2014. Kepersertaan Jaminan Kesehatan Nasional (JKN) bersifat wajib olehkarena itu BPJS Kesehatan menargetkan seluruh penduduk Indonesia yang berjumlah 257,5 juta jiwa dapat terdaftar sebagai peserta Jaminan Kesehatan Nasional paling lambat pada tanggal 1 Januari 2019. ${ }^{7}$ Kepesertaan Jaminan Kesehatan Nasional (JKN) setiap tahun meningkat. Pada tahun 2015 kepesertaan JKN bertambah sebesar 156,7 juta jiwa. Tahun 2016 kepesertaan menjadi 188,7 juta jiwa. Kepesertaan JKN terus berkembang menjadi 223 juta jiwa pada tahun 2017. Tahun 2018 jumlah peserta JKN total 235,1 juta jiwa $^{8}$ dan ditargetkan mencapai 257,5 juta jiwa atau seluruh penduduk Indonesia pada 2019 sebagai peserta Jaminan Kesehatan Nasional. Peningkatan kepesertaan tahun 2014 - 2018 tersebut dapat diartikan bahwa tingkat kesadaran masyarakat relatif baik terhadap jaminan kesehatan dan masyarakat sudah mengetahui manfaat pelayanan kesehatan dengan menjadi peserta JKN. Pernyataan tersebut sesuai dengan penelitian Suripto, kesadaran masyarakat di Kabupaten Bantul cukup baik dengan data sekitar $73 \%$ penduduk sudah menjadi peserta Jaminan Kesehatan Nasional. ${ }^{11}$ BPJS Kesehatan mempublikasikan data jumlah peserta JKN per 1 April 2019 sebesar 219.669.453 jiwa dengan rincian Penerima Bantuan Iuran - APBN (PBI-APBN) total 96.517.386 jiwa, Penerima Bantuan Iuran - APBD (PBI-APBD) dengan jumlah 35.925.726 jiwa, Pekerja Penerima Upah Pegawai Negeri (PPU-PN) sebesar 17.279.621 jiwa, Pekerja Penerima Upah Badan Usaha (PPU-BU) total 33.187.465 jiwa, Pekerja Bukan Penerima Upah (PBPU/Mandiri) sebesar 31.600.985 jiwa, dan Bukan Pekerja (BP) total 5.158.270 jiwa. $^{12}$ Peserta Jaminan Kesehatan Nasional (JKN) berdasarkan data yang diterbitkan BPJS Kesehatan per 1 April 2019 sebesar 219.669.453 jiwa dari 257,5 juta jiwa total penduduk Indonesia untuk mewujudkan Universal Health Coverage (UHC). Berdasarkan data tersebut peserta yang belum mendaftar sebagai peserta Jaminan Kesehatan Nasional (JKN) kurang lebih 37.830.547 jiwa dan diharapkan tahun 2019 seluruh penduduk Indonesia telah menjadi peserta JKN dengan begitu tercapainya UHC di Indonesia.

\section{KESIMPULAN}

Jumlah peserta JKN terus meningkat, per 1 April 2019 kepesertaan JKN 219.669.453 jiwa dari 257,5 juta jiwa seluruh penduduk dan diharapkan tahun 2019 Universal Health Coverage.

\section{SARAN}

Badan usaha yang belum mendaftarkan karyawan dan anggotanya diwajibkan segera mendaftarkan karyawannya di JKN dan bagi penduduk yang belum menjadi peserta JKN diwajibkan segera mendaftar dapat melalui kantor / website BPJS Kesehatan atau care center 1500400 , aplikasi Mobile JKN, e-DABU. 


\section{DAFTAR PUSTAKA}

1. Undang - Undang Dasar 1945

2. Subianto, Achmad. 2010. Sistem Jaminan Sosial Nasional. Jakarta: Gibon Books

3. Rys, Vladimir. 2011. Merumuskan Ulang Jaminan Sosial. Jakarta: Pustaka Alvabet

4. Undang - Undang No. 24 Tahun 2011

5. BPJS Kesehatan. 2016. Info BPJS Kesehatan Pentingnya Dukungan Pemda Untuk Mencapai Universal Health Coverage. Jakarta: Media Ekternal BPJS Kesehatan Edisi 44

6. BPJS Kesehatan. 2014. Kinerja BPJS Kesehatan Semester I Tahun 2014. Online. https://bpjskesehatan.go.id/bpjs/dmdocuments/f8f e78ba5206a7bf4f600a6b5fbd9591.pdf

7. Peraturan Presiden No. 82 Tahun 2018

8. BPJS Kesehatan. Panduan Praktis Tentang Kepesertaan dan Pelayanan Kesehatan yang Diselenggarakan oleh BPJS Kesehatan Berdasarkan Regulasi yang Sudah Terbit. Online. https://bpjs.kesehatan.go.id/bpjs/.../a9c 04aa825ffc12d24aeee668747f284.pdf

9. Peraturan BPJS Kesehatan No. 1 Tahun 2014

10.Suripto, Arip. 2017. Evaluasi Pelaksanaan Jaminan Kesehatan Nasional (Studi Tentang Hubungan Stakeholder, Model Pembiayaan dan outcome JKN di Kabupaten Bantul Provinsi Daerah Istimewa Yogyakarta). Journal of Governance and Public Policy. Vol. 4 No. 1 February

12. BPJS Kesehatan. Peserta Program JKN. Online. https://bpjskesehatan.go.id/bpjs/ 